Iván Efrén Sarmiento-Arévalo; Juan Carlos Erazo-Álvarez; Cecilia Ivonne Narváez-Zurita; Verónica Paulina Moreno

http://dx.doi.org/10.35381/r.k.v5i10.709

\title{
Estrategias de inclusión para el sistema financiero popular y solidario
}

Inclusion strategies for the popular and solidarity financial system

\author{
Iván Efrén Sarmiento-Arévalo \\ ivan.sarmiento@psg.ucacue.edu.ec \\ Universidad Católica de Cuenca, Cuenca \\ Ecuador \\ https://orcid.org/0000-0003-2871-1464 \\ Juan Carlos Erazo-Álvarez \\ jcerazo@ucacue.edu.ec \\ Universidad Católica de Cuenca, Cuenca \\ Ecuador \\ https://orcid.org/0000-0001-6480-2270 \\ Cecilia Ivonne Narváez-Zurita \\ inarvaez@ucacue.edu.ec \\ Universidad Católica de Cuenca, Cuenca \\ Ecuador \\ https://orcid.org/0000-0002-7437-9880 \\ Verónica Paulina Moreno \\ veronica.moreno@ucacue.edu.ec \\ Universidad Católica de Cuenca, Cuenca \\ Ecuador \\ https://orcid.org/0000-0003-1517-6124
}

Recibido: 20 de marzo de 2020

Revisado: 10 de abril de 2020

Aprobado: 02 de mayo de 2020

Publicado: 19 de mayo de 2020 
Revista Arbitrada Interdisciplinaria KOINONIA

Año V. Vol V. N¹0. Julio - Diciembre 2020

Hecho el depósito de Ley: FA2016000010

ISSN: 2542-3088

FUNDACIÓN KOINONIA (F.K). Santa Ana de Coro. Venezuela.

Iván Efrén Sarmiento-Arévalo; Juan Carlos Erazo-Álvarez; Cecilia Ivonne Narváez-Zurita; Verónica

Paulina Moreno

\title{
RESUMEN
}

El objetivo de este artículo es establecer lineamientos o estrategias dirigidas a las instituciones financieras locales para desarrollar programas que incentiven el acceso de productos financieros para la población sin excepción, estrategias que son parte de los mecanismos de inclusión financiera y serán explicadas dentro de esta investigación. El diseño de investigación utilizado es de tipo no experimental, de tipo transversal y descriptiva, con un enfoque cuantitativo - cualitativo. Los resultados encontrados reflejaron que la población del área rural del cantón Santa Isabel, es la que más dificultades tiene de acceder al sistema financiero atribuido a la distancia a las entidades financiera. El desarrollo de productos financieros acordes a las características socioeconómicas de la población incrementará su acceso al sistema financiero formal y generará en las instituciones financieras una mejor posición en su reputación.

Descriptores: Finanzas y comercio; cooperativa; sector informal; banco de desarrollo. (Palabras tomadas del Tesauro UNESCO).

\begin{abstract}
The objective of this article is to establish guidelines or strategies aimed at local financial institutions to develop programs that encourage access to financial products for the population without exception, that is, strategies that are part of the financial inclusion mechanisms and will be explained within this research. The research design used is non-experimental, cross-sectional and descriptive, with a quantitative-qualitative approach. The results found reflected that the population of the rural area of the Santa Isabel canton is the one that has more difficulties in accessing the financial system attributed to the distance from financial entities. The development of financial products according to the socioeconomic characteristics of the population will increase their access to the formal financial system and will generate a better position for financial institutions in their reputation.
\end{abstract}

Descriptors: Finance and trade; cooperatives; informal sector; development banks. (Words taken from the UNESCO Thesaurus). 
Revista Arbitrada Interdisciplinaria KOINONIA

Año V. Vol V. №10. Julio - Diciembre 2020

Hecho el depósito de Ley: FA2016000010

ISSN: 2542-3088

FUNDACIÓN KOINONIA (F.K). Santa Ana de Coro. Venezuela.

Iván Efrén Sarmiento-Arévalo; Juan Carlos Erazo-Álvarez; Cecilia Ivonne Narváez-Zurita; Verónica Paulina Moreno

\section{INTRODUCCIÓN}

El acceso a servicios financieros, está presente en la formulación de políticas públicas durante los últimos años dentro de América Latina, en algunos países con más énfasis que en otros. En el Ecuador no es la excepción, conjuntamente con el apoyo de organismos internacionales y el Banco Central del Ecuador (BCE) ejecuta, implementa y monitorea las políticas formuladas para incrementar el porcentaje de inclusión financiera dentro la población. Según estudios del propio BCE, con corte a diciembre de 2018 , sesenta y uno de cada cien ecuatorianos utiliza algún tipo de producto o servicio financieros, es decir que el $61 \%$ de los ecuatorianos son usuarios financieros y el restante el $49 \%$ no tienen acceso a una cuenta de ahorro, mucho menos a un producto de crédito dentro del sistema financiero ecuatoriano (Banco Central del Ecuador, 2020). Aunque el Ecuador ha buscado iniciativas para aumentar la inclusión financiera con la creación de nuevos canales para el acceso a los servicios como por ejemplo las billeteras móviles y los corresponsales bancarios; a pesar del esfuerzo, existe un desentendimiento de las autoridades públicas por implementar las regulaciones necesarias para que las instituciones financieras apliquen una estrategia nacional de inclusión financiera. El estudio Microscopio Global 2019 realizado por el Economist Intelligence Unit que analiza los avances en términos de elaboración e implementación de políticas utilizadas por los gobiernos y organismos reguladores para aumentar la inclusión financiera, concluye que el Ecuador ha descendido un puesto en el ranking al comparar el año 2017 con el año 2018, causado por la falta de una estrategia integral para la inclusión financiera (Economist Intelligence Unit, 2019).

En lo que respecta al acceso de servicios financieros por provincias, no se cuenta con estudios estadísticos, que permita tener datos comparativos y analizar la evolución de la inclusión en los últimos años. Sin embargo, en las series históricas publicadas por el BCE, se observan las cuentas de ahorro abiertas desagregados por provincias, en donde se puede indicar que en la provincia del Azuay al cierre del año 2018 existían 614.773 cuentas de ahorro abiertas, que corresponden 327.105 hombres y 287.668 
Iván Efrén Sarmiento-Arévalo; Juan Carlos Erazo-Álvarez; Cecilia Ivonne Narváez-Zurita; Verónica Paulina Moreno

corresponden a mujeres, lo que faltaría determinar es el número de habitantes de la provincia que no tienen acceso a un producto financiero (Banco Central del Ecuador, 2020).

El cantón Santa Isabel, objeto de estudio de esta investigación, se ubica en la zona sur oeste de la provincia del Azuay, Ecuador, con una población que reside en mayor proporción en el área rural, en donde predomina actividades económicas agrícolas, comerciales y de transporte. Es una zona en donde existe la cultura del manejo de productos financieros, por lo que es un mercado apetecible para las instituciones financieras que buscan tener presencia física en el cantón. En el momento de realizar esta investigación existen tres entidades financieras privadas como son los bancos y cuatro instituciones financieras de la Economía Popular y Solidaria como son las cooperativas de ahorro y crédito.

En el documento se presenta a la inclusión financiera, como parte del desarrollo socio económico de las personas de escasos recursos. Promover el acceso de productos y servicios financieros son un factor fundamental para la generación de ese desarrollo, y no solo para la población de bajos ingresos, sino también para pequeños, microempresarios e informales, siendo un derecho para la población interrelacionarse con las instituciones del sistema financiero. Para contextualizar la inclusión financiera, se menciona la definición que realiza la Asociación Global para la Inclusión Financiera (GPFI, por sus siglas en inglés) y el Grupo Consultivo de Ayuda a los Pobres (CGAP, por sus siglas en inglés) que consideran la siguiente definición de inclusión financiera:

Se refiere a una situación en la que todos los adultos en edad de trabajar, incluidos aquellos actualmente excluidos del sistema financiero, tienen acceso efectivo a los siguientes servicios financieros provistos por las instituciones formales: crédito, ahorro (incluyendo cuentas corrientes), pagos y seguros (Asociación Global para la Inclusión Financiera \& Grupo Consultivo de Ayuda a los Pobres, 2011).

Partiendo de ese concepto, el acceso a productos financieros básicos como la apertura de una cuenta de ahorros, incentiva una cultura de previsión de recursos económicos, 
Iván Efrén Sarmiento-Arévalo; Juan Carlos Erazo-Álvarez; Cecilia Ivonne Narváez-Zurita; Verónica Paulina Moreno

siendo el comienzo para el uso de otros servicios financieros como son: envío y recepción de transferencias, créditos, compra de seguros y otros productos financieros más avanzados (Banco Central del Ecuador, 2012). Una cuenta de ahorros básica, puede solicitarse sin monto mínimo de apertura y sin la presentación de documentos, de donde podrá realizar transferencias, pagos de servicios y podrán transaccionar electrónicamente (Junta de Política y Regulación Monetaria y Financiera, 2019).

Sin embargo, existen inconvenientes para que una persona se desmotive en la apertura de cuentas de ahorro y otros productos. Entre uno de los obstáculos se menciona la falta de educación financiera como un problema fundamental a combatir. La educación financiera conlleva a las personas a tener nociones básicas desde el uso y beneficios de los productos financieros, la interpretación del cálculo de los intereses cobrados o pagados hasta conceptos técnicos más avanzados, desarrollando aptitudes para la administración de las finanzas personales y de sus negocios (Corporación Andina de Fomento, 2017).

Otros de los obstáculos o barreras para la inclusión financiera están las limitaciones geográficas, el costo que se genera de trasladarse de los domicilios a las entidades financieras se incrementa según mayor sea la distancia. Se menciona también las limitaciones socioeconómicas como una de las principales barreras, en donde se encuentran aspectos como los altos costos del sistema financiero, la falta de conocimiento de los costos de productos informales contra los formales y la falta de documentación, referencias o garantías que alejan a las personas en lo que respecta al uso del crédito (Rodríguez-Raga \& Riaño-Rodríguez, 2016).

Frente a esta situación, para elevar el desarrollo socio económico del Ecuador y específicamente del cantón Santa Isabel, es vital que todas las personas y en especial la población de bajos recursos económicos localizadas en las zonas rurales, posean las mismas oportunidades para mejorar sus condiciones de vida. En consecuencia, para esta investigación, se determina que la falta de acceso de la población del cantón Santa Isabel a los productos o servicios financieros que ofertan las instituciones financieras es 
Iván Efrén Sarmiento-Arévalo; Juan Carlos Erazo-Álvarez; Cecilia Ivonne Narváez-Zurita; Verónica Paulina Moreno

el problema para solucionar. Se pretende confirmar cual es la relevancia de los diferentes aspectos que impiden la inclusión financiera dentro de la población objeto de estudio, que conlleva a la informalidad y la posible desconfianza en el sistema financiero ecuatoriano.

Por consiguiente, este artículo tiene como finalidad, generar estrategias que promuevan a las personas con exclusión financiera del cantón Santa Isabel, puedan acceder a servicios financieros y así disminuir la pobreza, generar fuentes de empleo, distribuir equitativamente la riqueza, dinamizar la economía solidaria y fomentar el desarrollo social. En cuanto al acceso, lo óptimo es que todos los segmentos de la población puedan utilizar los servicios financieros y que los mismos estén diseñados y adecuados para su inserción. Los requisitos y barreras de entrada deben ser mínimos, para que sean asequibles para todos. Así mismo la proximidad a las instituciones de economía popular y solidaria mediante la utilización de herramientas tecnológicas, con precios accesibles.

\section{Referencial teórico}

\section{Inclusión financiera, una visión global.}

Existen diferentes sucesos que causan cierto impacto en el desarrollo de la población que pertenece a sectores desfavorecidos y que se caracterizan por situarse en territorios que son considerados poco desarrollados, entre estos acontecimientos se puede mencionar la falta de acceso a servicios públicos, ausencia de recursos materiales para intercambiar por bienes de consumo, carencia de educación, etc. El porvenir de una comunidad no se sitúa en forma exclusiva en un aspecto económico o material, aunque si es muy importante, existen otros factores que discrimina a cierta población de participar y vivir plenamente dentro de la sociedad.

Una persona puede no tener recursos económicos o no tiene los suficientes, pero no quiere decir que se encuentra en exclusión. Pare recoger los diversos factores que afectan a la sociedad que de alguna manera se encuentra desprotegida, emerge el 
Iván Efrén Sarmiento-Arévalo; Juan Carlos Erazo-Álvarez; Cecilia Ivonne Narváez-Zurita; Verónica Paulina Moreno

término de exclusión social. Se entiende como exclusión social a la dificultad de los individuos que no le permite la participación en algunos sistemas de funcionamiento colectivo. Según (García-Roca, 1998) existen diferentes elementos que serían parte de la exclusión relacionados con los factores subjetivos, sicológicos y personales, en donde se establecen dimensiones o procesos de la exclusión social.

Las perturbaciones repentinas, que afectan las economías de los países en el mundo han permitido identificar nuevas formas de pobreza y vulnerabilidad y nuevos factores de exclusión social, uno de estos factores es la exclusión financiera (Zubeldia, Grajirena, Sogorb \& Zubiaurre, 2008). Los mismos autores aportan que la exclusión financiera se debe a la dificultad u obstáculo de los individuos para utilizar algún tipo de producto financiero, como consecuencia de las dificultades en el acceso, sus condiciones de vida, costos por traslados, desconocimiento o la autoexclusión en base a experiencias o percepciones negativas

Por situaciones como las mencionadas, para muchas familias con un alto índice de sobreendeudamiento y con sueldos bajos, resulta prácticamente imposible adquirir productos financieros de ahorro a corto o largo plazo, lo que compromete su porvenir ante el inevitable decrecimiento de sus ingresos. Es por esta razón, que ya no contratarán un seguro para cubrir riesgos trascendentes como la salud, no solo por la pérdida de poder adquisitivo, sino por el incremento del valor de las primas acompañado del desmejoramiento de su calidad de vida. Además, encontrarán cada día más dificultades para acceder al crédito, recurriendo cada vez más a préstamos de familiares y amigos, en el peor de los casos, a los llamados prestamistas ilegales, que cobran una tasa muy superior a lo permitido legalmente.

Se puede mencionar como causales de la exclusión financiera el bajo nivel educativo de los adultos, seguido de la falta de dinero para constituir un ahorro, la distancia de las agencias de las entidades financieras y el costo que incurren en su traslado, además de la falta de documentos formales que son parte de los requisitos de aperturas y la desconfianza que erróneamente perciben al sistema financiero. Tampoco es 
Iván Efrén Sarmiento-Arévalo; Juan Carlos Erazo-Álvarez; Cecilia Ivonne Narváez-Zurita; Verónica Paulina Moreno

descartable que exista un proceso de autoexclusión del sistema bancario, debido a la pérdida de confianza en el sector tras los escándalos financieros de instituciones reconocidas en el mercado, además de las crisis financieras mundiales. Razones, que podrían alterar la percepción ciudadana con respecto al valor añadido que incorporan los productos financieros.

Si se analiza la exclusión financiera a nivel mundial, el (Banco Mundial, 2018) en su publicación de Inclusión Financiera actualizada en abril del año 2018, estima que cerca de dos mil quinientas millones de personas que carecen de productos financieros formales y el $75 \%$ de las personas de bajos recurso no tienen libretas de ahorros, se afirma que la inclusión es un pilar fundamental para disminuir la indigencia y promover el bienestar. Estos porcentajes de inclusión financiera en los países de las Américas de habla hispana y África no han tenido una evolución positiva en los últimos años. Aunque se observa también que en los países desarrollados existe también un porcentaje reducido de población que no tiene acceso al sistema financiero.

Otras instituciones que aportan con sus estudios es financiera europea (Oikocredit, 2015), dentro de su informe de exclusión financiera, explica que tanto el acceso a la tecnología como la capacitación, el impulso constante de microfinanzas y la cooperación económica dentro de las zonas rurales, impulsan el mejoramiento de la inclusión social y financiera dentro de las esferas menos favorecidas de todos los países. Aunque lo cierto es que falta mucho por hacer, la pregunta es si los servicios financieros disponibles en el mercado crean inclusión.

Así mismo, (Roa-García, Alonso-Másmela, García-Bohórquez \& Rodríguez-Pinilla, 2018) indican que existen 1.700 millones de individuos, que no tienen experiencia en el uso de productos microfinancieros, en donde el $56 \%$ pertenecen al género femenino. Las mujeres predominan dentro de los adultos que están bancarizados tanto en los países con un alto índice de exclusión financiera como lo son China e india, así como en los países en donde existe un alto índice de bancarización como Bangladesh y Colombia. 
Iván Efrén Sarmiento-Arévalo; Juan Carlos Erazo-Álvarez; Cecilia Ivonne Narváez-Zurita; Verónica Paulina Moreno

En lo referente al continente americano, el índice de inclusión financiero es menor en comparación con los países de economías de ingresos altos. Dentro de la encuesta y su respectivo análisis del estudio realizado por Global Findex del Banco Mundial en el año 2014, menciona que en América Latina el 51\% de adultos utiliza una libreta de ahorros en una entidad bancaria o microfinanciera, un valor definitivamente menor si se compara con el $91 \%$ de las personas adultas bancarizados que se ubican en los países de ingresos altos (Pérez \& Titelman, 2018).

El informe Findex del año 2018, muestra ligeros avances en la comparación de cuentas de ahorro de personas adultas entre los años 2014 al 2017, con un índice de bancarización del 54,4\%, que demuestra un incremento del tres por ciento en los avances de inclusión financiera en la región en esos últimos años. Sin embargo, el número de adultos no bancarizados en América Latina y el Caribe que corresponde al 45,6\% (207 millones de personas), sigue siendo preocupante (El Economista, 2018). Así mismo, la Federación Latinoamericana de Bancos (2018), observa la composición de los adultos no bancarizados por diversos componentes, como por ejemplo el género en América Latina y el Caribe existe un porcentaje del $56 \%$ de mujeres no titulares de cuenta contra un $44 \%$ de varones. El $50 \%$ de personas más pobres no son bancarizadas al igual que el $39 \%$ que no tienen un empleo formal.

\section{Educación Financiera y su aporte en la inclusión.}

En este sentido, (La Corporación Andina de Fomento, 2017), en su informe, explica que los países de América Latina han dado pasos importantes para en Inclusión Financiera, mediante la oferta de servicios financieros y distribución de agencias y corresponsales de las entidades que prestan estos servicios. Aunque, reconoce que la utilización de productos financieros aún es limitado, debido en gran parte a la escaza educación financiera (EF) de la población. Autores como (Conolly \& Khaldoun, 2001), considera que la educación financiera ha sido aceptada mundialmente como uno de los principales elementos para combatir la exclusión social y la promoción del ingreso a la 
Iván Efrén Sarmiento-Arévalo; Juan Carlos Erazo-Álvarez; Cecilia Ivonne Narváez-Zurita; Verónica Paulina Moreno

bancarización. Conocimientos que deben desarrollarse desde edades tempranas, inculcando el deseo de ahorro que permitan a las personas administrar mejor sus inversiones, (Roy \& Zeckhauser, 2015) consideran que la carencia de Educación Financiera es uno de los elementos primordiales en las últimas crisis financieras en los diferentes países del mundo.

En consecuencia, sin una comprensión de las nociones financieras básicas, los adultos no bancarizados no están capacitados para decidir la contratación o no de productos de ahorro y crédito. Las personas con alfabetización financiera tienen una visión más amplia para aceptar servicios financieros con respecto al ahorro, la inversión, el préstamo y más. La inducción de técnicas y conceptos financieros es fundamental en tiempos en los que los productos de bancarización son difíciles de comprender y son utilizables para todo tipo de personas. Por ejemplo, con los gobiernos de muchos países que presionan para impulsar el acceso a los servicios financieros, el incremento de adultos con una titularidad de un producto de ahorro y el acercamiento a productos de préstamos sigue en crecimiento.

Además, los cambios en la responsabilidad para decidir sobre la inversión de sus pensiones transfieren a los participantes que anteriormente dependían de sus empleadores o gobiernos para su seguridad financiera después de la jubilación (Klapper, Lusardi \& Van-Oudheusden, 2015). El desconocimiento de estas nociones financieras, traen consigo costos significativos. Algunos usuarios no comprenden el concepto de los intereses en el transcurso del tiempo, lo que resulta en altas comisiones de transacción, aumentan las deudas e incurren en tasas de interés más altas en los créditos.

Así mismo, caen en una burbuja de sobrendeudamiento y gastando más de lo que ingresa por sus salarios. En comparación con los beneficios que brinda el aprendizaje de planificación financiera que son mayores. Los adultos con las suficientes capacidades financieras planifican mejor el trabajo y ahorro para la jubilación. Los inversores que tienen capacidades financieras sólidas tienden a diversificar los riesgos 
Iván Efrén Sarmiento-Arévalo; Juan Carlos Erazo-Álvarez; Cecilia Ivonne Narváez-Zurita; Verónica Paulina Moreno

mediante la difusión de fondos en varias empresas (Klapper, Lusardi \& VanOudheusden, 2015).

Para medir el avance de la educación financiera, existen múltiples organismos internacionales y regionales que realizan sus informes para medir el nivel conocimiento financiero de cada país. Las instituciones reconocidas son el Banco Mundial, OCDE, Personal Finance Index (P-Fin Index), Centro de Estudios Monetarios Latinoamericanos (CEMLA), Comisión Económica para América Latina y el Caribe (CEPAL), etc.; las mismas que con su equipo de investigadores o colaborando en conjunto, desarrollan sus propias investigaciones y publicaciones, generando estudios importantes, calificación y ranking en base a las encuestas aplicadas en los países en donde generan impacto.

Por ejemplo, en una encuesta reciente y publicada por la OCDE en el año 2016, se elabora el ranking de los países que poseen el índice de mejor educación financiera, basándose en encuestas realizadas a 52.000 personas mayores de edad, en donde se evaluó los conocimientos en temas financieros, utilizando una escala con un valor máximo de 30 puntos, tomando en cuenta el discernimiento y comportamiento en lo que respecta el dinero de los individuos. El listado lo lideran los países europeos en los tres primeros lugares está Francia (14,9), Finlandia $(14,8)$ y Noruega $(14,6)$. En el cuarto lugar Canadá siendo el mejor representante de América con 14,6. Como representante de Asia está Hong Kong con 14,4 en el quinto puesto. Brasil como representante de América Latina dentro del lugar 26 con 12,2 (Radio Programas del Perú, 2016).

En lo que respecta a América Latina, los organismos multilaterales encargados de evaluar los avances en educación financiera son el CEPAL, CAF, CEMLA, BID, Federación Latinoamericana de Bancos (FELABAN), etc. Además, de asociaciones de Bancos que toman los estudios generales en el continente y la comparan con los resultados de sus países. Como referencia se tiene el estudio realizado por la (Corporación Andina de Fomento, 2017), describiendo que América Latina ha conseguido avances importantes en la EF, con una tendencia en crecimiento de 
Iván Efrén Sarmiento-Arévalo; Juan Carlos Erazo-Álvarez; Cecilia Ivonne Narváez-Zurita; Verónica Paulina Moreno

apertura de servicios, como lo son las ventanillas de pago, sucursales bancarias, número de cajeros automáticos entre otros. Sin embargo, su uso todavía es limitado por las personas no bancarizadas, producto del bajo nivel de cultura financiera dentro de sus conocimientos.

Cabe recalcar que en América Latina existe todavía un alto desconocimiento de conceptos financieros como tasas de interés, rentabilidad en relación con los riesgos, tasa de inflación y la manera que funcionan los mercados de capitales. Las cifras que muestra (Asobancaria, 2016), demuestran que menos de la población comprende los significados de tasas de interés, inflación y un porcentaje menor que comprende o no es posible calcular el poder adquisitivo de un producto ante el incremento de la inflación. Así mismo el estudio realizado por la (Corporación Andina de Fomento, 2017), concluye que existen brechas importantes de EF, en los países de la región.

\section{Avances de la inclusión financiera}

Los gobiernos de América Latina, con la intención de promover EF y por consiguiente la inclusión financiera, están desarrollando e implementando políticas y regulaciones para que los bancos centrales y sus sistemas financieros, promuevan el aumento de la cultura financiera (Roa-García, Alonso-Másmela, García-Bohórquez \& RodríguezPinilla, 2014). Los programas de EF que están ejecutándose están encaminados especialmente en conocimientos económicos - financieros, como expresa la encuesta realizada por la CEPAL (2016) en donde existe un ochenta y uno por ciento de los países analizados que aplican estos objetivos, con mayor énfasis en los programas empleados por los bancos centrales. El $63 \%$ de los programas se enfocan en la defensa del consumidor y un $56 \%$ de programas fomenta la inclusión financiera.

Los principales públicos objetivos de los programas de EF son dirigidos a todas las personas en general, sin existir una especialización particular sobre el tipo de personas, edad o alguna característica relevante, que hace dudar que se tengan resultados positivos, y es que la experiencia en educación recomienda adaptar estos programas a 
Iván Efrén Sarmiento-Arévalo; Juan Carlos Erazo-Álvarez; Cecilia Ivonne Narváez-Zurita; Verónica Paulina Moreno

un público definido. En América Latina y el Caribe, existe un alto porcentaje de países (81\%) que se apoyan en alianzas interinstitucionales para la elaboración e implementación de programas de EF, en donde son partícipes las instituciones del sector privado y en menor proporción las instituciones del estado (CEPAL, 2016). Otra conclusión de los resultados de la encuesta se desprende que los cinco medios o canales importantes, por donde se transmite la EF, dentro del continente americano son presentaciones en público (88\%), folletos educativos (81\%), páginas web $(69 \%)$, competiciones $(63 \%)$ y eventos $(56 \%)$.

De lo antes expuesto, se puede decir que la educación financiera consiste en implementar propuestas para formar la cultura, costumbre financiera de los individuos, brindando conocimientos, instrumentos, capacidades para tomar decisiones, fomentando la confianza de los diferentes sistemas financieros nacionales, y el crecimiento de su región. La EF aporta a que las personas adopten servicios financieros ajustados a sus condiciones particulares y familiares, que mejor satisfagan a sus requerimientos o necesidades. Si existe una parte de la población que no posea nociones financieras, existe el riesgo a que las mismas se vean afectadas por las inesperadas crisis económicas locales, regionales y mundiales que golpean a los países. El desarrollo de una EF desde la infancia es un pilar fundamental para evitar caer en las afecciones de las crisis financieras.

\section{Estrategias de inclusión financiera}

En esta parte de la teoría, es importante mencionar el papel de las instituciones financieras en el incremento del uso de los servicios financieros. Es importante destacar la iniciativa de la empresa privada que cae en las instituciones financieras, cooperativas y mutualistas de ahorro, organizaciones sin fines de lucro, y demás instituciones que han establecido sus mercados objetivos en zonas rurales y urbanas sin bancarización, como una forma de devolver sus ganancias hacia la sociedad. Si se habla de inversión socialmente responsable, se entiende la incorporación de criterios económicos, criterios 
Iván Efrén Sarmiento-Arévalo; Juan Carlos Erazo-Álvarez; Cecilia Ivonne Narváez-Zurita; Verónica Paulina Moreno

ambientales y sociales. Este tipo de misión de las instituciones genera una imagen reputacional positiva dentro de las organizaciones, que actualmente es un factor de decisión para los clientes o consumidores en el momento de decidir la compra. En este sentido, las empresas con una responsabilidad social empresarial (RSE) bien consolidada son catalogadas como potenciales recibidores de inversión, así como también de proyectos de mejor y asistencia técnica. La RSE enfocada a la inclusión financiera, debe implementarse como un sistema programado, en donde se definan objetivos medibles a conseguir (Urgilés-Urgilés, Erazo-Álvarez, \& Narváez-Zurita, 2019). En lo que respecta las estrategias para el acceso a servicios financieros, cada país formula a través de sus bancos centrales, la estrategia nacional de inclusión financiera (ENIF) en donde se plantean la elaboración de políticas públicas que incentiven tanto a las instituciones financieras como a los individuos que no poseen un servicio financiero, se motiven a la utilización de canales y servicios bancarios, (Cortéz, 2018) describe que existen modelos exitosos de inclusión financiera, como los que se implementan en algunos países de África, como por ejemplo Kenia, que utiliza la telefonía celular como medio de pago para sus transacciones.

Uno de los desafíos es utilizar la tecnología digital para aumentar la inclusión financiera. (Demirgüç-Kunt, Klapper, Singer, Ansa \& Hess, 2018) aportan información sobre las propiedades de los teléfonos celulares y su acceso al internet, revelando grandes oportunidades para que las personas aperturen una cuenta, así como también para aquellos que ya tienen una cuenta y no la utilizan. Es de suponer, que los avances tecnológicos y digitales por sí, no incrementara la bancarización de las personas. Una estrategia para incentivar el uso de los servicios digitales dentro de la población es generando sistemas de transferencias y pagos en línea sólidos, con una estructura física adecuada, acompañados de políticas de protección a las instituciones intermediarias y usuarios finales (Lema-Guiracocha, Erazo-Álvarez, \& Narváez-Zurita, 2019). 
Iván Efrén Sarmiento-Arévalo; Juan Carlos Erazo-Álvarez; Cecilia Ivonne Narváez-Zurita; Verónica Paulina Moreno

(Demirgüç-Kunt, Klapper, Singer, Ansa \& Hess, 2018), explican que el diseño de los productos financieros que pueden ser de forma analógica o digital, deben adecuarse a los requerimientos y habilidades de las personas que por primera vez utilizarán estos tipos de servicios. La característica de estos usuarios es que pertenecen a una población pobre o desfavorecida con un alto porcentaje de predominio de mujeres. La (Federación Latinoamericana de Bancos, 2018), en su informe complementa que la tecnología celular y el internet ha abierto las puertas de un futuro digital que es difícil de predecir en un futuro de mediano plazo. Los servicios financieros basados en innovación digital son vistos como la esperanza que romperá los paradigmas de las personas no bancarizadas utilizan para no utilizar los productos financieros. Por citar un ejemplo, el uso de dinero digital a través de los celulares elimina los costos y la duración de trasladarse a una oficina de una institución financiera. Con la reducción de costos del manejo del dinero, el acceso a los servicios tecnológicos se incrementará.

\section{MÉTODO}

El diseño de esta investigación es de tipo no experimental, las variables analizadas no se puede ejercer algún tipo de manipulación, sino que son observadas en el momento de realizar la recolección de los datos. Es de tipo transversal, se preparó la información en base de un periodo de tiempo específico, así mismo se utilizó la metodología de investigación tipo descriptiva, en donde se busca puntualizar las características de la población del cantón Santa Isabel que está en un estado de exclusión financiera, además de describir los procesos que las instituciones financieras locales aportan a la bancarización del sector.

De acuerdo a la forma de recolectar la información, se utilizó un enfoque cuantitativo y un enfoque cualitativo; el primero porque usa la recolección de datos para probar las hipótesis planteadas, teniendo como base la medición numérica de los datos recopilados y su correspondiente análisis estadístico, para establecer patrones y el comportamiento de las características de la población analizada; el segundo, porque el 
Iván Efrén Sarmiento-Arévalo; Juan Carlos Erazo-Álvarez; Cecilia Ivonne Narváez-Zurita; Verónica Paulina Moreno

enfoque se basa en métodos de recolección de datos que no tienen un estándar específico (Hernández, Fernández \& Baptista, 2014). La recopilación de datos consistió en obtener información relacionada con las personas que están dentro de la inclusión financiera y compararlas con aquellas que no utilizan servicio financiero alguno (JimboEspinoza, Erazo-Álvarez, \& Narváez-Zurita, 2019).

En relación a los métodos de investigación utilizados, se empleó el inductivo deductivo, tomando en consideración lo que afirma (Dávila-Newman, 2006) en la aplicación de este método, deductivo porque se partió de la premisa que solamente la población de bajos recursos no accede a servicios financieros, se obtuvo conclusiones específicas sobre diversos factores que inciden en la inclusión financiera, es decir inició desde lo general hasta lo específico. Inductivo porque partimos de varias consideraciones acerca del problema, para extraer una conclusión en general.

Además, se aplicó el método histórico - lógico para estructurar la teoría en que se basa el artículo y relacionar con el objetivo de esta investigación. Al mismo tiempo se utilizó el método analítico - sintético en donde primeramente se realizó una descomposición de las características de la variable independiente, posteriormente mediante un proceso de razonamiento, comprender los aspectos y las relaciones de esta variable. Por último se empleó el método sistémico para construir las estrategias propuestas para incrementar el nivel de inclusión financiera de la población del cantón Santa Isabel.

\section{Universo de estudio y tratamiento muestral}

En consecuencia, que la población objeto de estudio comprende a la población del cantón Santa Isabel que, en el año 2020 no utiliza algún tipo de servicio financiero ya sea, cuenta de ahorros, créditos o seguros, al no contar con el tamaño del universo a investigar y para realizar la estimación de la muestra de una población infinita se aplicó la siguiente fórmula:

$$
\mathrm{n}=\frac{\mathrm{Z}^{2} \mathrm{pq}}{\mathrm{B}^{2}}
$$


Iván Efrén Sarmiento-Arévalo; Juan Carlos Erazo-Álvarez; Cecilia Ivonne Narváez-Zurita; Verónica Paulina Moreno

En donde el valor de $z$ es de 1,96 con un intervalo de confianza del 95\%, la frecuencia esperada p se utilizó un valor de 0,5 ; la variable q es el resultado de restar 1 - q; con un error admitido B del 10\%; (Mateu \& Casal, 2003). Al resolver la fórmula con los valores expuestos, el resultado del tamaño de la muestra es de 96 personas.

\section{RESULTADOS}

En la figura 1 se presenta un esquema del desarrollo de la propuesta, que detallan los aspectos a desarrollar.

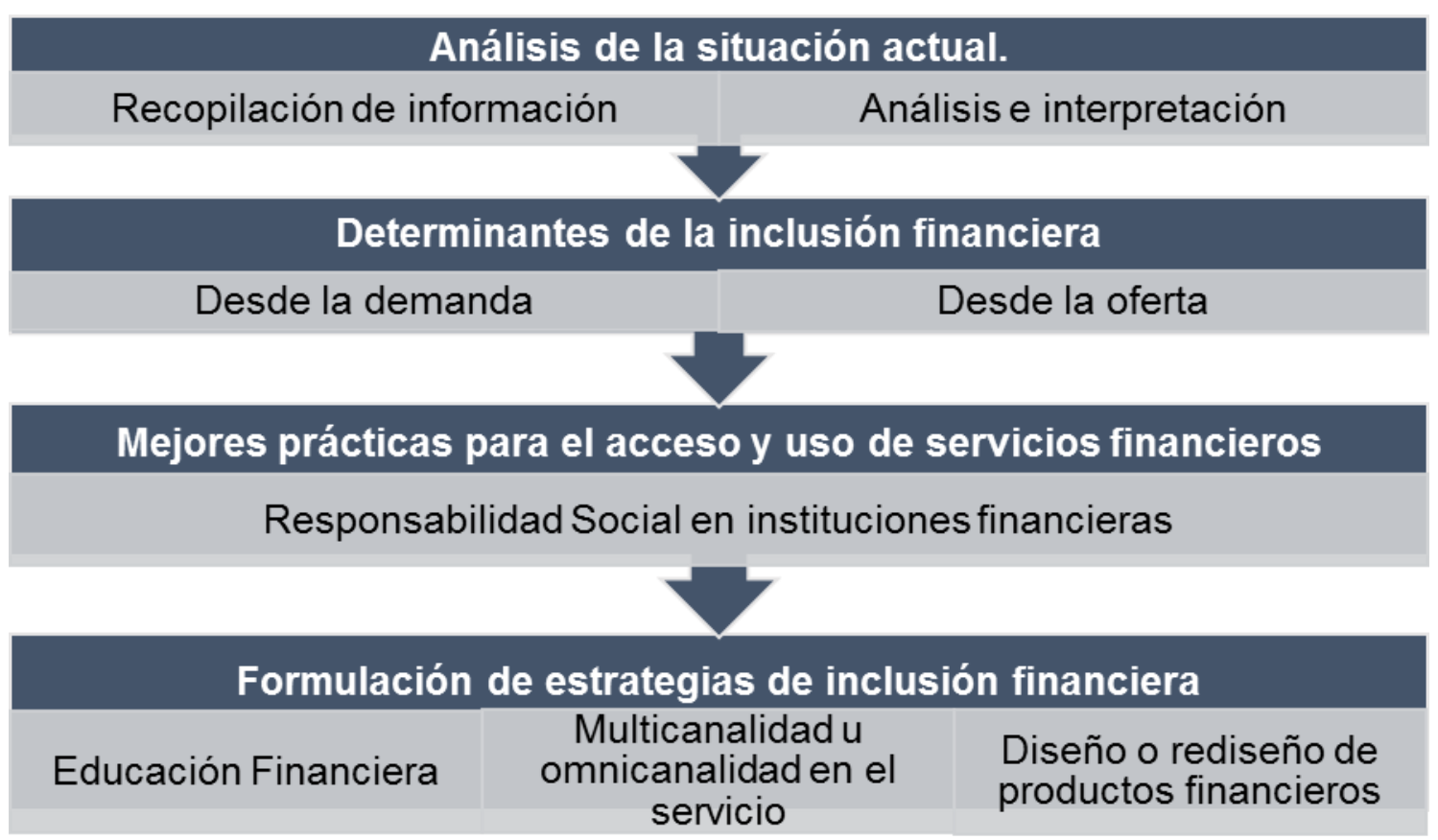

Figura 1. Planteamiento de la propuesta.

\section{Análisis de la situación actual}

\section{Recopilación de información}

Para la recolección de información, se han definido grupos de variables que servirán para encontrar las relaciones necesarias e interpretar los resultados obtenidos. Explorar las características sociodemográficas de la población objeto de estudio, permitirá 
Iván Efrén Sarmiento-Arévalo; Juan Carlos Erazo-Álvarez; Cecilia Ivonne Narváez-Zurita; Verónica Paulina Moreno

encontrar aspectos comunes entre los investigados que se utilizará para la segmentación de estrategias a formularse, características que se presentan en la siguiente tabla:

\section{Tabla 1}

Características de la población

\begin{tabular}{ll} 
Variable & Descripción \\
\hline Género & Género del encuestado \\
Edad & Edad del encuestado \\
Estado Civil & Estado civil del encuestado \\
Ingreso & Ingreso del encuestado \\
Vivienda & Si es propia o arrendada \\
Domicilio & $\begin{array}{l}\text { Ubicación domicilio del encuestado, rural o } \\
\text { urbano }\end{array}$ \\
\hline
\end{tabular}

Fuente: Elaboración Propia

Igualmente se definen variables para determinar el uso de servicios financieros del encuestado y su entorno familiar, además de variables para establecer el nivel de educación financiera que tienen los habitantes del cantón Santa Isabel, las que se presentan en las siguientes tablas: 
Iván Efrén Sarmiento-Arévalo; Juan Carlos Erazo-Álvarez; Cecilia Ivonne Narváez-Zurita; Verónica Paulina Moreno

\section{Tabla 2}

Incidencia de las variables en el uso de una cuenta de ahorro

\begin{tabular}{ll} 
Variable & Descripción \\
\hline Inclusión & $\begin{array}{l}\text { Si tiene una cuenta de ahorro. } \\
\text { Razón por la que el encuestado no } \\
\text { usa servicios financieros }\end{array}$ \\
Razón & $\begin{array}{l}\text { Si un familiar tiene una cuenta de } \\
\text { ahorros. } \\
\text { Cuenta familiar }\end{array}$ \\
Multicanales & $\begin{array}{l}\text { Idifica la reacción con la de los servicios. } \\
\text { cercania de }\end{array}$
\end{tabular}

Fuente: Elaboración Propia

\section{Tabla 3}

Nivel de educación financiera

\begin{tabular}{ll} 
Variable & Descripción \\
\hline Cobros & $\begin{array}{l}\text { Si realiza cobros de algún tipo de } \\
\text { bono o remesa. } \\
\text { Conoce los beneficios de tener } \\
\text { una cuenta de ahorros }\end{array}$ \\
Beneficios ahorros & $\begin{array}{l}\text { Identifica la aplicación de tasa de } \\
\text { interés } \\
\text { Conoce si puede transaccionar } \\
\text { desde celular }\end{array}$ \\
\hline
\end{tabular}

Fuente: Elaboración propia

\section{Análisis e interpretación de los resultados.}

Según los resultados obtenidos en las encuestas, se han clasificado los grupos de variables para su análisis correspondiente. Se determina los aspectos demográficos, económicos y de conocimientos financieros de la población del cantón Santa Isabel, 
Iván Efrén Sarmiento-Arévalo; Juan Carlos Erazo-Álvarez; Cecilia Ivonne Narváez-Zurita; Verónica Paulina Moreno

que no acceden a un servicio o producto bancario en las instituciones financieras del lugar.

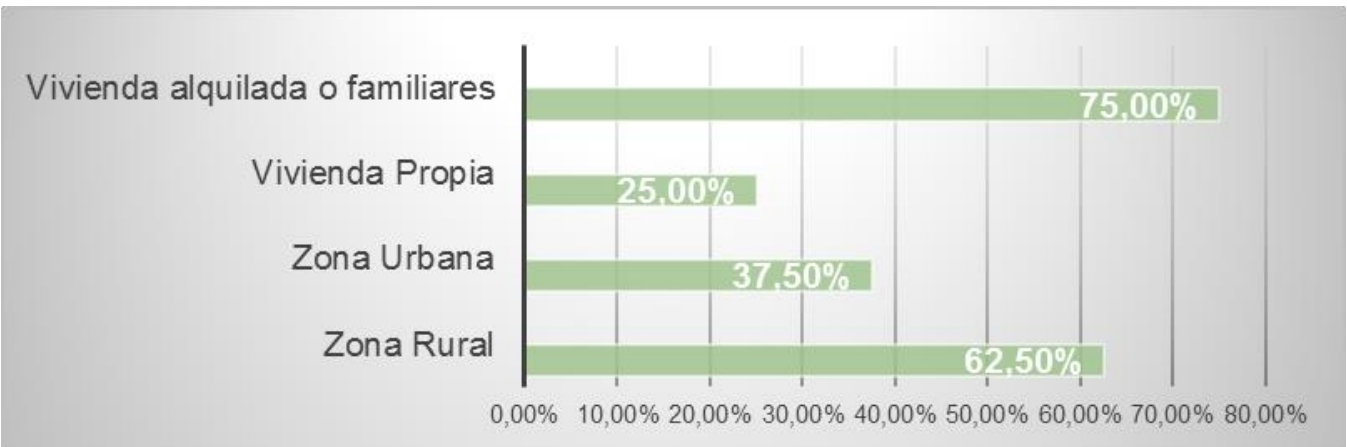

Figura 2. Relación entre la inclusión financiera con el tipo de vivienda y domicilio.

Los resultados presentados en la figura 2, demuestran que el $75 \%$ de la población que no accede al sistema financiero no tiene vivienda propia, sino que arrienda o vive en la residencia de familiares, en comparación del restante $25 \%$ de encuestados. Se observa además que la mayor parte de los encuestados reside en el área rural con el 62,50\% en comparación con el 37,50\% en el área urbana.

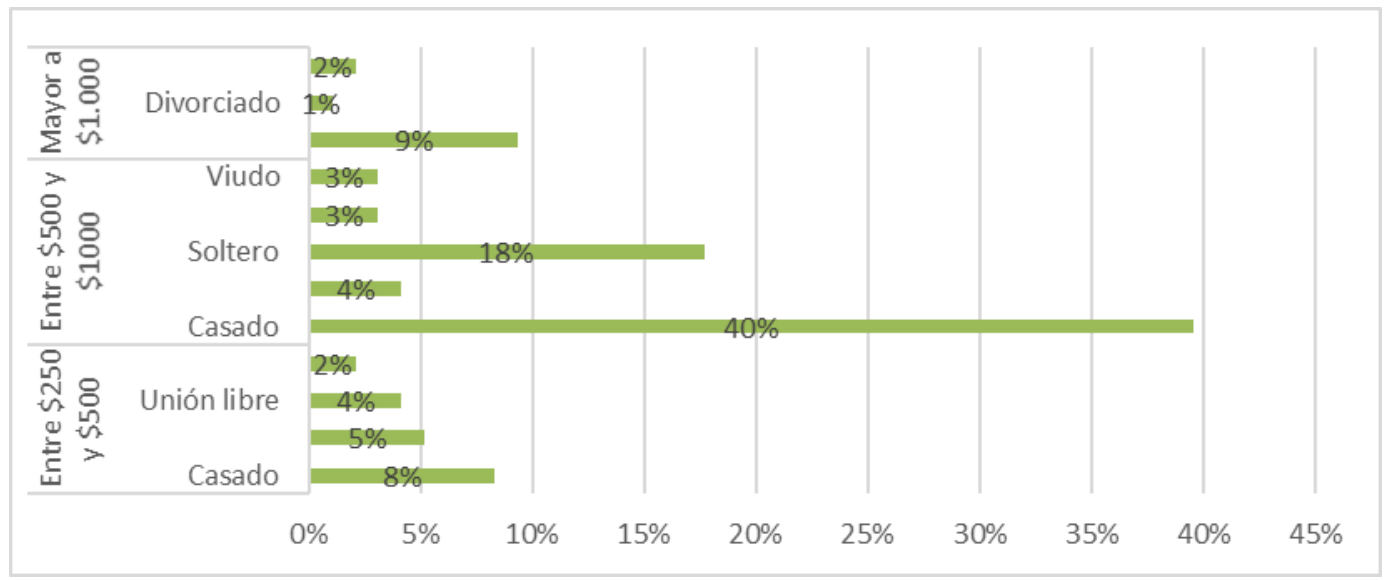

Figura 3. Relación entre los rangos de ingresos y la edad de la población encuestada. 
Iván Efrén Sarmiento-Arévalo; Juan Carlos Erazo-Álvarez; Cecilia Ivonne Narváez-Zurita; Verónica Paulina Moreno

El estado civil de los encuestados se concentra en mayor parte en casado y soltero en $57 \%$ y $23 \%$ respectivamente. El ingreso familiar se encuentra en mayor fracción dentro del rango entre quinientos y mil dólares con un $68 \%$.

Los resultados de los factores que inciden en el uso de una cuenta de ahorro, según su incidencia, se presentan en el siguiente gráfico:

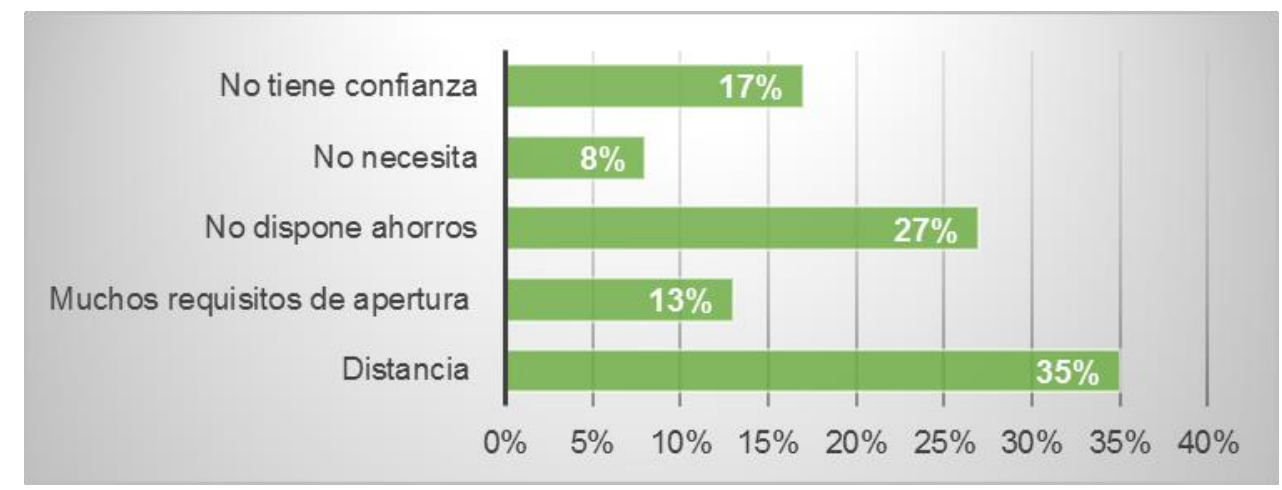

Figura 4. Incidencia de las variables en el uso de cuentas de ahorro.

Como uno de los factores más importantes para que las personas no utilicen servicios financieros, es la distancia entre sus domicilios y la institución financiera con un 35\%, seguido con un $27 \%$ que no dispone de ahorros. El $17 \%$ de los encuestados dice no necesitar servicios financieros, el $13 \%$ menciona que los requisitos de manejo de las cuentas como el principal obstáculo para no utilizar servicios financieros y el $8 \%$ mencionó la desconfianza en las instituciones financieras. 
Iván Efrén Sarmiento-Arévalo; Juan Carlos Erazo-Álvarez; Cecilia Ivonne Narváez-Zurita; Verónica Paulina Moreno

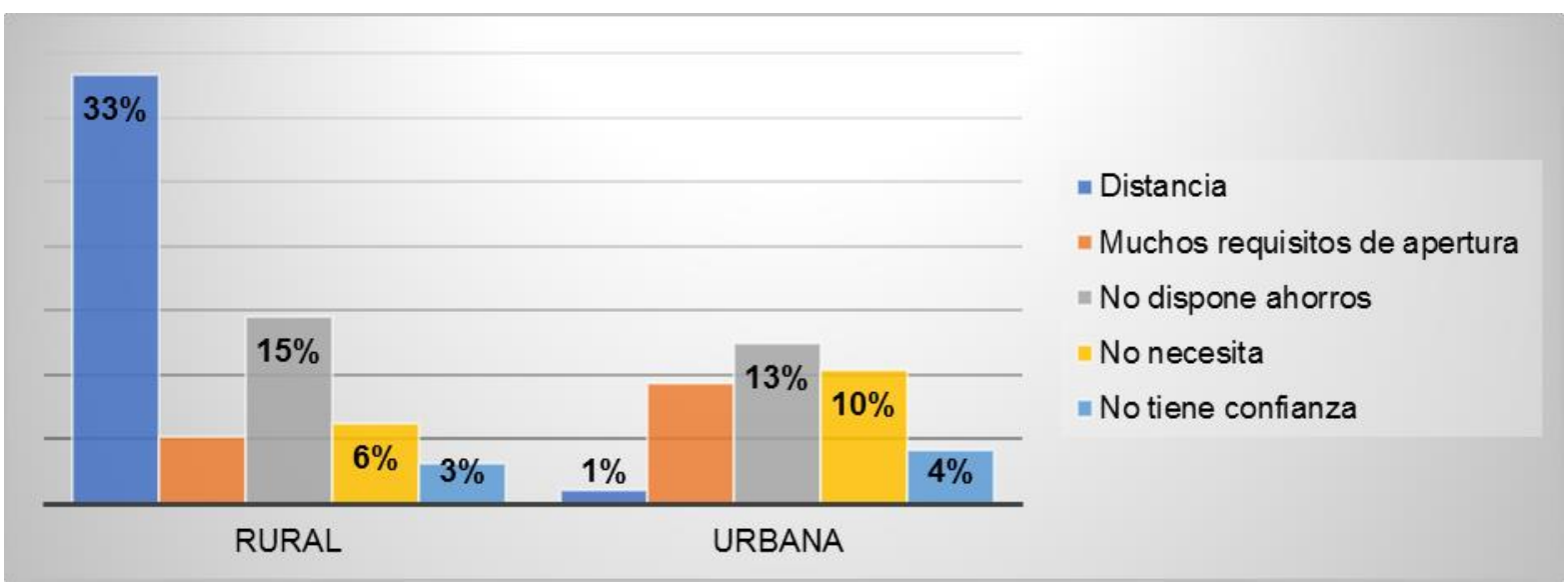

Figura 5. Comparación del área rural y urbana.

En la figura 5 se compara los obstáculos de la inclusión financiera entre la población encuestada del área rural contra la urbana del cantón Santa Isabel, en donde se presenta que para el área rural la principal causa para no mantener una cuenta de ahorros es la distancia entre su domicilio y la entidad financiera, seguida de la no disponibilidad de dinero para el ahorro. En cambio, en el sector urbano la principal causa es la no disponibilidad de ahorros, seguido de la no necesidad de utilizar los servicios financieros.

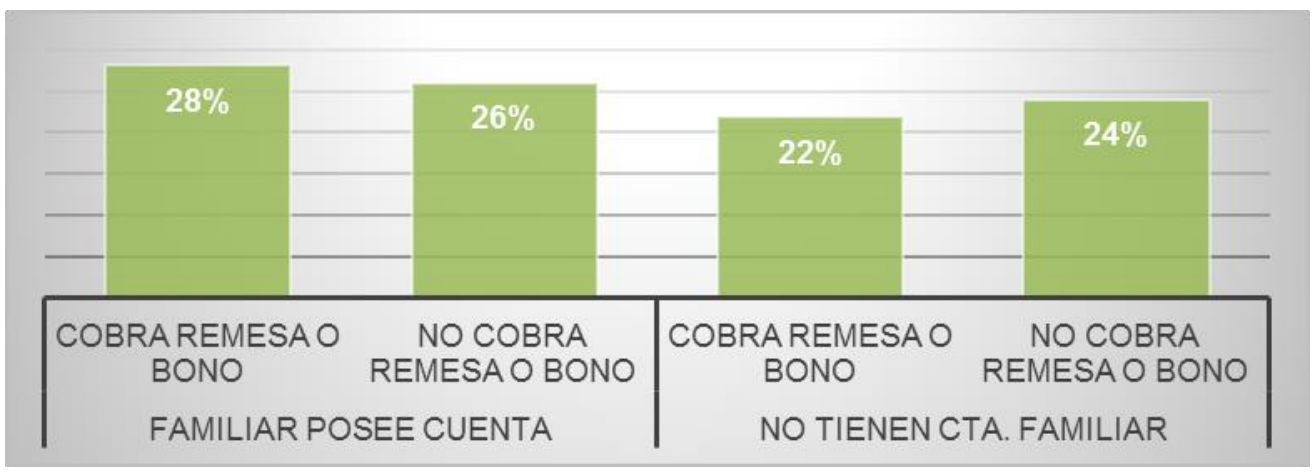

Figura 6. Comparación del área rural y urbana. 
Iván Efrén Sarmiento-Arévalo; Juan Carlos Erazo-Álvarez; Cecilia Ivonne Narváez-Zurita; Verónica Paulina Moreno

Como se presenta en la figura anterior, el $54 \%$ de los encuestados manifiesta que dentro de su hogar un familiar posee una cuenta de ahorro, que puede ser una razón para la no apertura de una cuenta. Así como también se observa que el 50\% de los encuestados visita algún tipo de institución que puede ser financiera para cobros de bonos o remesas, este acercamiento es una oportunidad para las instituciones para atraer a potenciales clientes para la oferta de productos de ahorros en donde se vean acreditados los valores a cobrar.

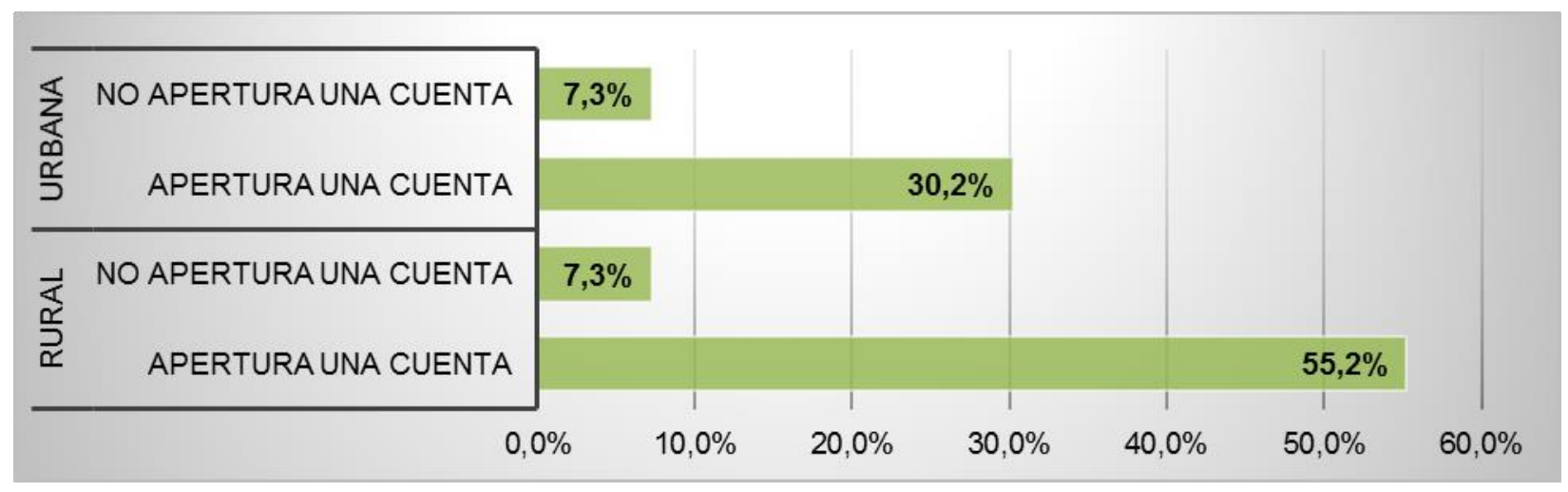

Figura 7. Incidencia de corresponsales y cajeros en la intención de abrir una cuenta.

En la figura anterior muestra que las personas encuestadas cuyo determinante para no abrir una cuenta es la distancia del domicilio hasta las entidades financieras, el $86,4 \%$ contestó que abriría una cuenta si es que existiría un corresponsal, banco del barrio u cajero automático cerca de su domicilio. La tendencia es mayor en el área rural en comparación con la urbana. 
Iván Efrén Sarmiento-Arévalo; Juan Carlos Erazo-Álvarez; Cecilia Ivonne Narváez-Zurita; Verónica Paulina Moreno

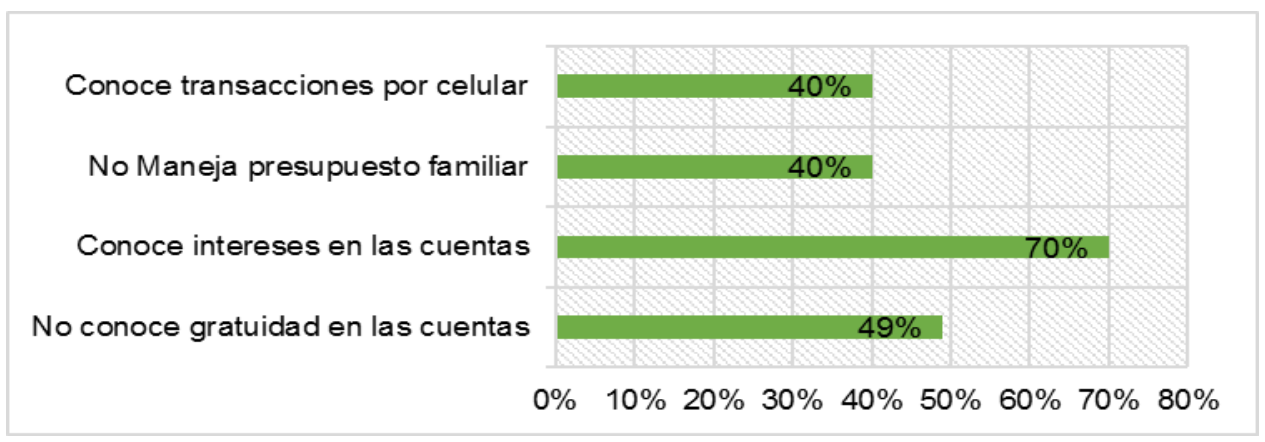

Figura 8. Nivel de educación financiera.

Dentro de los encuestados, se observa que existen desconocimientos en algunos conceptos financieros. El $49 \%$ desconoce que no existen costos por apertura y manejo de las cuentas de ahorro. El $40 \%$ de la población encuestada no maneja un presupuesto de ingresos versus gastos, así mismo existe el $40 \%$ de los encuestados desconoce que existe la transaccionalidad mediante móvil o celular. En cambio, el 70\% de los encuestados si conoce que al abrir una cuenta de ahorro le cancelan un valor por intereses, aunque no termina convenciendo que lo haga.

\section{Determinantes de la inclusión financiera}

\section{Barreras desde el punto de vista de la demanda}

En base a la relación existente entra la variable inclusión y si la persona entrevistada tiene o no vivienda propia, relacionado también si la ubicación de su domicilio está en el área urbana o rural, se determina que existe una mayor exclusión financiera en las personas que no tienen vivienda propia y viven en el área rural del cantón Santa Isabel. La principal barrera es la distancia de sus domicilios a las instituciones financieras, esto sumado a los bajos ingresos de los encuestados no permite que un servicio financiero sea rentable para su desmejorada economía. 
Iván Efrén Sarmiento-Arévalo; Juan Carlos Erazo-Álvarez; Cecilia Ivonne Narváez-Zurita; Verónica Paulina Moreno

\section{Barreras desde el punto de vista de las instituciones financieras (oferta)}

Se analiza la información de las instituciones financieras locales, en donde se extrae información acerca de los productos financieros ofertados a la población.

Las corresponsalías estaban permitidas desde muchos años atrás solamente para entidades como los bancos con programas conocidos como "El banco del barrio" y "Mi vecino", en donde se realizan transacciones de pagos y con menos frecuencia de cuentas de ahorro. De los análisis realizados se observa que una institución cooperativa, con la aprobación correspondiente, ha implementado un programa agresivo de expansión de puntos de atención como son las corresponsalías, sin embargo, la ubicación de las mismas está situadas mayormente en la zona urbana.

Existen productos financieros generales y estándares, es decir los mismos productos de ahorro en todas las instituciones, demostrando falta de innovación y adaptabilidad al cambio. La falta de promoción de cuentas básicas para sectores vulnerables se evidencia en las entidades financieras, así mismo no existen créditos de microfinanzas con la tecnología apropiada para ese segmento.

En lo que respecta a la carencia de educación financiera, es necesario que los intermediarios sean más transparentes, con información desglosada sobre las tasas, retenciones y costos de los servicios y productos financieros. La inadecuada comunicación de los valores a cancelar, pueden ocasionar una interpretación incorrecta al momento de tomar los servicios, lo que genera efectos negativos en la reputación de la institución, cuyo impacto puede perdurar en el tiempo.

\section{Mejores prácticas para el acceso y uso de servicios financieros}

Existen entidades que en los últimos años están enfocadas en ampliar su cobertura en diferentes mercados con la promoción de sus productos. Las estrategias implementadas, están diseñadas acorde a las características de la población, como son distancia entre la oferta y demanda de los productos financieros, disponibilidad de tecnología en el mercado, incremento de cajeros automáticos, servicios por internet, 
Iván Efrén Sarmiento-Arévalo; Juan Carlos Erazo-Álvarez; Cecilia Ivonne Narváez-Zurita; Verónica Paulina Moreno

aplicaciones móviles y demás servicios para facilitar la transaccionalidad a los clientes. Los bancos dentro del Ecuador, cada vez están buscando estrategias para penetrar en el mercado de las microfinanzas, que es un segmento que ha sido explotado por las cooperativas de ahorro y crédito. Es por eso que buscando estrategias de cobertura de mercado el Banco de Guayaquil y Banco de Pichincha lanzó los denominados "Bancos del barrio" y "Mi vecino" que son corresponsales bancarios, que permiten realizar transacciones de pago de servicios, depósitos y pagos en cuentas de ahorro. Dentro de las cooperativas de ahorro y crédito, la pionera en este tipo de servicios es la cooperativa Jardín Azuayo, que desde el año 2019, puso a consideración corresponsales bancarios en las distintas provincias en donde tienen presencia mediante agencias. Así mismo, esta misma institución ofrece los llamados botón de pagos como una alternativa de la tarjeta de crédito, que permiten realizar compras mediante una aplicación móvil.

En lo que respecta al tema de educación financiera, el aporte que se evidencia dentro de la provincia del Azuay, es el realizado por la Fundación de las Cajas de Ahorro de Alemania (Sparkassenstiftung) para la Cooperación Internacional, que desde el año 2018 ejecuta sus programas con la colaboración de instituciones públicas e instituciones financieras. La implementación de programas como "Yo y mis finanzas", así como la formación de facilitadores expertos en educación financiera ha sido el inicio de una serie de programas y proyectos que en coordinación con instituciones públicas y privadas lleva a delante esta fundación para el fortalecimiento de temas financieros dentro de la población.

\section{Formulación de estrategias de inclusión financiera}

Con los resultados obtenidos en la presente investigación, se han determinado las razones o causas por que la población del cantón Santa Isabel, no acceden a servicios dentro del sistema financiero nacional. Tomando en cuenta los conceptos expuestos, se formulan las siguientes estrategias, para que sean acogidas por las instituciones 
Revista Arbitrada Interdisciplinaria KOINONIA

Año V. Vol V. N¹0. Julio - Diciembre 2020

Hecho el depósito de Ley: FA2016000010

ISSN: 2542-3088

FUNDACIÓN KOINONIA (F.K). Santa Ana de Coro. Venezuela.

Iván Efrén Sarmiento-Arévalo; Juan Carlos Erazo-Álvarez; Cecilia Ivonne Narváez-Zurita; Verónica Paulina Moreno

financieras que tienen influencia en el cantón.

\section{Tabla 3}

Estrategias de Inclusión

\section{Estrategias}

Acercar a las personas que residen lejos de la zona urbana mediante, productos con características tecnológicas accesibles para todas las personas. Implementar el uso de aplicaciones móviles para el pago de servicios contra la cuenta de ahorros, serán estimulantes para las personas que viven lejos de lugares poblados, disminuirá sus gastos por traslados y por el día de trabajo perdido. Las aplicaciones móviles permiten transaccionar y consultar movimientos en su cuenta de ahorro.

Transparentar los servicios financieros ofertados de una forma clara y concisa a los potenciales y antiguos usuarios, para no generar desconfianza y una imagen reputacional negativa de las instituciones financieras. La utilización de cuentas básicas dentro de la población son servicios no implementados o poco promocionados, por no ser atractivos financieramente. Los usuarios de estas cuentas, serán aquellos que tienen una escaza capacidad para ahorrar, así como los que cobran algún tipo de bono por parte del estado.

Emprender planes de educación financiera desde la temprana edad y a grupos con un nivel de exclusión. En el cantón Santa Isabel, no existen programas de educación financiera que sean constantes y dirigido a población de diversas edades, sino se realizan eventos con cierta parte de la población y en determinadas fechas en el año, lo que no permite evaluar el impacto de estos eventos. Las instituciones financieras locales deberían incluir como un objetivo social la educación financiera de la población, el mismo que podrá ser evaluado dentro de su balance social cooperativo.

La educación financiera debería estar incluida dentro de las políticas públicas para que sea desarrollado desde temprana edad. Sin embargo, el Gobierno Autónomo Descentralizado Municipal de Santa Isabel, podría adoptar una posición de colaboración con las instituciones públicas (como las educativas del cantón), para desarrollar eventos masivos con diferentes tipos de capacitados, sean estos, escolares, colegiales, artesanos, microempresarios, etc.

Las instituciones financieras deben enfocarse a implementar corresponsalías en sectores más alejados de la zona urbana, permitiendo que las personas del área rural accedan con un menor costo a la utilización de servicios financieros y no financieros, como parte de su responsabilidad social. Se observa que existe una cantidad mayor de corresponsalías en el área urbana, cuando lo ideal es que se localizan en las parroquias y comunidades aledañas. El desarrollo de corresponsales bancarios en las zonas rurales, mediante una comunicación y promoción adecuada facilitará el incremento de usuarios financieros. 


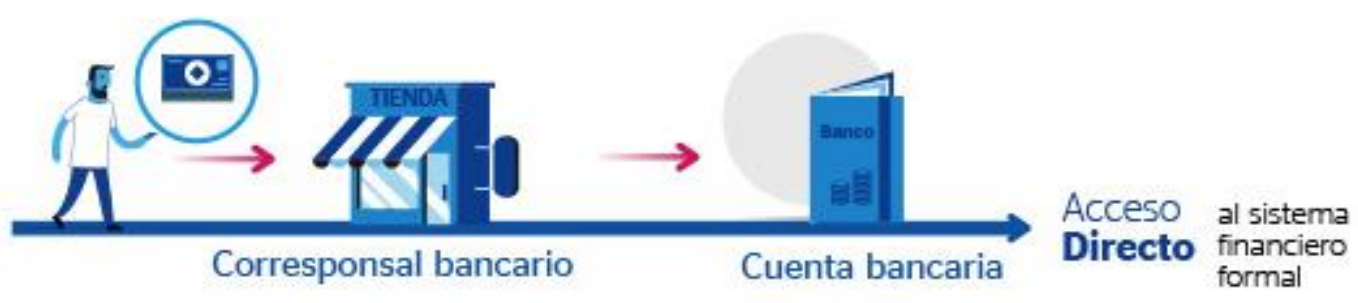

Figura 9. Implementación de un corresponsal bancario.

\section{CONCLUSIONES}

Las instituciones financieras para promover la inclusión financiera deben tener en cuenta las características socioeconómicas de la población del cantón Santa Isabel, con el propósito de buscar soluciones dirigidas al sector no bancarizado. Pero sin la información necesaria, los individuos no tienen el conocimiento y por ende no pueden manejar sus recursos ni los procesos que se requieren para tener acceso a los productos y servicios financieros que promueven las instituciones bancarias.

La distancia y el bajo poder de ahorro de la población no permite el acceso al sistema financiero formal. En el cantón Santa Isabel, existen diferentes instituciones financieras, pero las mismas están ubicadas dentro del área urbana del cantón lo que discrimina a cierta parte de la población al no uso principalmente de productos de ahorro. Con los resultados obtenidos se concluye que no existe una oferta de servicios acorde a las personas que viven en el área rural o distante de las instituciones financieras como también para aquellas personas que no pueden generar un excedente de liquidez que permita generar un ahorro que pueda ser utilizado en casos urgentes para su bienestar personal. La implementación de la propuesta generará un valor agregado a las instituciones financieras, que permitirá una posición adecuada dentro de su comunidad y lealtad entre sus integrantes.

\section{FINANCIAMIENTO}

No monetario. 
Revista Arbitrada Interdisciplinaria KOINONIA

Año V. Vol V. N¹0. Julio - Diciembre 2020

Hecho el depósito de Ley: FA2016000010

ISSN: 2542-3088

FUNDACIÓN KOINONIA (F.K). Santa Ana de Coro. Venezuela.

Iván Efrén Sarmiento-Arévalo; Juan Carlos Erazo-Álvarez; Cecilia Ivonne Narváez-Zurita; Verónica Paulina Moreno

\section{AGRADECIMIENTO}

A la población del cantón Santa Isabel por permitir la realización de esta investigación.

\section{REFERENCIAS CONSULTADAS}

Asobancaria (2016). Programas de Educación Financiera en Latinoamérica: un énfasis en el caso colombiano. [Financial Education Programs in Latin America: an emphasis on the Colombian case]. Recuperado de https://n9.cl/ojbt

Asociación Global para la Inclusión Financiera \& Grupo Consultivo de Ayuda a los Pobres (2011). Global Standard-Setting Bodies and Financial Inclusion for the Poor: Towards Proportionate Standards and Guidance. [Organismos mundiales de establecimiento de normas e inclusión financiera para los pobres: hacia normas y orientaciones proporcionales]. Recuperado de https://n9.cl/e5fp

Banco Central del Ecuador (2012). Inclusión Financiera: Aproximaciones teóricas y prácticas. [Financial inclusion: theoretical and practical approaches]. Recuperado de https://n9.cl/9c5s

Banco Central del Ecuador (2020). Cifras de inclusión financiera están ahora en la plataforma Bl del Banco Central [Financial inclusion figures are now on the BI platform of the Central Bank]. Recuperado de https://n9.cl/t7vig

Banco Mundial. (2018). Inclusión Financiera. [Financial inclusion]. Recuperado de https://n9.cl/ob92i

Comisión Económica para América Latina y el Caribe. (2016). Inclusión financiera de las pymes en el Ecuador y México. [Financial inclusion of SMEs in Ecuador and Mexico]. Recuperado de https://n9.cl/at8m

Connolly, C, \& Khaldoun H. (2001). Financial services and social exclusión, Financial Services. [Servicios financieros y exclusión social, Servicios financieros]. Consumer Policy Centre-University of New South Wales-Chifley Research Centre, Sydney 
Iván Efrén Sarmiento-Arévalo; Juan Carlos Erazo-Álvarez; Cecilia Ivonne Narváez-Zurita; Verónica Paulina Moreno

Corporación Andina de Fomento (2017). La inclusión y educación financiera en América Latina: oportunidades y desafíos. [Financial inclusion and education in Latin America: opportunities and challenges]. Recuperado de https://n9.cl/ucmp5

Cortéz, J. (2018). Kenia: el laboratorio financiero de África. [Kenya: Africa's financial laboratory]. Recuperado de https://n9.cl/ysde

CEPAL (2016). Estudio Económico de América Latina y el Caribe 2016: La Agenda 2030 para el Desarrollo Sostenible y los desafíos del financiamiento para el desarrollo. [Economic Survey of Latin America and the Caribbean 2016: The 2030 Agenda for Sustainable Development and the challenges of financing for development]. Recuperado de https://n9.cl/jcpz

Dávila-Newman, G. (2006). El razonamiento inductivo y deductivo dentro del proceso investigativo en ciencias experimentales y sociales [Inductive and deductive reasoning within the research process in experimental and social sciences]. Recuperado de https://n9.cl/radvz

Demirgüç-Kunt, A, Klapper, L, Singer, D, Ansa, S, \& Hess, J. (2018). Medición de la inclusión financiera y la revolución de la tecnología financiera. [Measuring financial inclusion and the financial technology revolution]. Recuperado de https://n9.cl/rba9

Economist Intelligence Unit. (2019). Microscopio Global de 2019: El entorno propicio para la inclusión financiera. [2019 Global Microscope: The enabling environment for financial inclusion.]. Recuperado de https://n9.cl/1wmia

El Economista (2018). Inclusión financiera en América Latina. [Financial inclusion in Latin America]. Recuperado de https://n9.cl/3trx7

Federación Latinoamericana de Bancos (2018). IV Informe de inclusión financiera. [IV Financial inclusion report]. Recuperado de https://n9.cl/5d5w

García-Roca, J. (1998). Exclusión social y contracultura de la solidaridad. [Social exclusion and counterculture of solidarity.]. España: HOAC.

Hernández Sampieri, R., Fernández Collado, C., \& Baptista Lucio, M. (2014). Metodología de investigación. [Research methodology.]. México: McGraw-Hill. 
Iván Efrén Sarmiento-Arévalo; Juan Carlos Erazo-Álvarez; Cecilia Ivonne Narváez-Zurita; Verónica Paulina Moreno

Jimbo-Espinoza, G. C., Erazo-Álvarez, J. C., \& Narváez-Zurita, C. I. (2019). Análisis de eficiencia de la cartera de crédito en la Cooperativa de Ahorro y Crédito Jardín Azuayo, mediante el modelo análisis envolvente de datos. [Efficiency analysis of the credit portfolio in the Azuayo Garden Credit and Savings Cooperative]. 593 Digital Publisher CEIT, 97-113. Recuperado de https://n9.cl/p02v

Junta de Política y Regulación Monetaria y Financiera (2019). [Monetary and Financial Policy and Regulation Board.]. Resolución No. 518-2019-F. Recuperado de https://n9.cl/kyba

Lema-Guiracocha, P., Erazo-Álvarez, J., \& Narváez-Zurita, C. (2019). El talento humano, factor clave para la gestión organizacional en Instituciones de intermediación financiera. [Human talent, a key factor for organizational management in financial intermediation institutions.]. Revista Arbitrada Interdisciplinaria Koinonía, 4(1), 349-375. http://dx.doi.org/10.35381/r.k.v4i1.461

Mateu, E., \& Casal, J. (2003). Tamaño de la muestra. [Sample size]. Epidem Med Prev, 1, 8-14. Recuperado de https://n9.cl/meyz

OECD (2005). Improving Financial Literacy: Analysis of Issues and Policies. [Mejora de la educación financiera: análisis de cuestiones y políticas.] París: OECD Publishing. https://doi.org/10.1787/9789264012578-en

Oikocredit (2015). Exclusión social y exclusión financiera, un mal endémico de nuestra sociedad. [Social exclusion and financial exclusion, an endemic evil of our society]. Recuperado de https://n9.cl/h752

Pérez, E., \& Titelman, D. (2018). La inclusión financiera para la inserción productiva y el papel de la banca de desarrollo. [Financial inclusion for productive insertion and the role of development banking]. Santiago: Libros de la CEPAL, № 153. Recuperado de https://n9.cl/p5of

Radio Programas del Perú (2016). Los 10 países con mejor educación financiera según la OCDE. [The 10 countries with the best financial education according to the OECD]. Recuperado de https://n9.cl/1uwe2 
Revista Arbitrada Interdisciplinaria KOINONIA

Año V. Vol V. N¹0. Julio - Diciembre 2020

Hecho el depósito de Ley: FA2016000010

ISSN: 2542-3088

FUNDACIÓN KOINONIA (F.K). Santa Ana de Coro. Venezuela.

Iván Efrén Sarmiento-Arévalo; Juan Carlos Erazo-Álvarez; Cecilia Ivonne Narváez-Zurita; Verónica Paulina Moreno

Red de Instituciones Financieras de Desarrollo (2017). Estudio de Inclusión financiera en Ecuador 2017: Acceso y uso de servicios financieros. [Financial Inclusion Study in Ecuador 2017: Access and use of financial services]. Quito. Recuperado de https://n9.cl/skij

Rodríguez-Raga, S., \& Riaño-Rodríguez, F. F. (2016). Determinantes del acceso a los productos financieros en los hogares colombianos. [Determinants of access to financial products in Colombian households]. Estudios Gerenciales, 32(138), 1424. http://dx.doi.org/10.1016/j.estger.2015.11.004

Roy, D., \& Zeckhauser, R. (2015). The anatomy of ignorance: diagnoses from literature. [La anatomía de la ignorancia: diagnósticos de la literatura.]. Routledge International Handbook of Ignorance Studies, 61-73. Recuperado de https://n9.cl/yb32

Roa-García, M, Alonso-Másmela, G, García-Bohórquez, N, \& Rodríguez-Pinilla, D. (2014). Educación e inclusión financiera en América Latina y el Caribe. [Education and financial inclusion in Latin America and the Caribbean]. Recuperado de https://n9.cl/q505z

Klapper; L, Lusardi, A, \& Van-Oudheusden, P. (2015). Financial Literacy around the World. [Alfabetización financiera alrededor del mundo]. Recuperado de https://n9.cl/y9ag

Urgilés-Urgilés, S. L., Erazo-Álvarez, J. C., \& Narváez-Zurita, C. I. (2019). El coaching y la productividad laboral en la Cooperativa de Ahorro y Crédito de la Pequeña Empresa Biblián Ltda. [Coaching and labor productivity at the Biblián Small Business Savings and Credit Cooperative Ltd.]. Revista Arbitrada Interdisciplinaria Koinonía, 1(4); 408-435. http://dx.doi.org/10.35381/r.k.v4i1.463

Zubeldia, A. M., Grajirena, J. M., Sogorb, A. O., \& Zubiaurre, M. Z. (2008). Reflexiones sobre el origen y las implicaciones de la Exclusión Financiera. [Reflections on the origin and implications of financial exclusion]. Universidad, Sociedad y Mercados Globales, 209-218. Recuperado de https://n9.cl/u2z9

C2020 por los autores. Este artículo es de acceso abierto y distribuido según los términos y condiciones de la licencia Creative Commons Atribución-NoComercial-Compartirlgual 4.0 Internacional (CC BY-NC-SA 4.0)

(https://creativecommons.org/licenses/by-nc-sa/4.0/). 